\title{
Organizational attractiveness and person job fit as the predictors of intention to stay of employees commercial bank
}

\author{
Onanong Kaothan* \\ Faculty of Applied Arts, King Mongkut's University of Technology North Bangkok, Bang Sue», Bangkok, Thailand
}

\author{
Keywords \\ Organizational attractiveness \\ Person job fit \\ Intention to stay
}

Received: 10 April 2018

Accepted: 15 May 2018

Published: 6 June 2018

\begin{abstract}
This study aims to 1) study the level of organizational attractiveness, person-job fit, and intention to stay. 2) To study the relationship between organizational attractiveness and intention to stay. 3) To study the relationship between person-job fit and intention to stay. 4) To predict intention to stay with organizational attractiveness and person-job fit. The sample of the research was the employees' sample of 406 people. The research instrument was questionnaires. Statistics used were frequency, percentage, mean, standard deviation, Pearson's correlation coefficient, and stepwise multiple regression analysis. The results revealed that 1) Organizational attractiveness was at a high level, the person-job fit was at a high level, and the intention to stay as high. 2) There was a positive relationship between organizational attractiveness and intention to stay $(r=.589)$ with a statistical significance level of .013) There was a positive relationship between person-job fit and intention to stay $(r=.612)$ with a statistical significance level of .014) Organizational attractiveness and person-job fit accounted for 40.3 percent of the variance in intention to stay of employees. The current research provides a guideline for developing procedures for the recruitment and selection of Human Resources staff. Including workforce planning. Budget planning and the good image of the organization to benefit other organizations.
\end{abstract}

(C) 2018 The Author(s). Published by TAF Publishing.

\section{INTRODUCTION}

From the circumstances of business systems from past to present, financial institutions are very important financial intermediaries and the institution that is most active in the economy is the commercial bank. Commercial banks were started in the country in Thailand for the first time in the reign of King Rama 4 of Rattanakosin on 2 December 1431. Currently, commercial banks have a variety of services including deposits in various types, Mortgage loan service, advising investment, service pay utility bills, foreign services, service about rent of safety deposit box, assurance services in various types and many other forms of service. Because the banking system is financially relevant, therefore, commercial banks are the organizations that must pay attention to the image of the organization to ensure the reliability of customers and the general public.
One important element that will affect the organization's image is the personnel. It is the power to drive the system in the right direction. The human resources of each bank must have a good and effective human resource plan. In recruiting employees in the financial industry and maintaining quality personnel in the system, the key to maintaining a good person in the organization is to understand what factors motivate these individuals to remain with the organization (Husain \& Husin, 2017; Kulesa, 2003; Rehman, 2017). Job retention is something the organization must consider as a priority in order to have enough staff to achieve the goals of the organization and reduce the problem about turnover of employee in the organization. The job retention means when personnel get what they need from the organization, people will intend to stay in the organization (Dasig Jr, 2017; Li, 2017; Mathis, 2006)

\footnotetext{
* corresponding author: Onanong Kaothan

†email: Ohjubjib@gmail.com
} 
(Taiwan, Na. Nan, \& Ngudgratoke, 2017; M. Tsai, 2017). Factors influencing employee's intention to stay in the workplace can be classified as employees' characteristics, Task, Organization Characteristic, Compensation, and Employee relationship.

In the financial industry today, the competition is very high. In terms of performance, organizational image, and financial products, the human needs to respond to the problem in the mind. Commercial banks are increasingly adopting advanced technologies to develop their systems and products. At the same time, the work of the banking system is necessary to involve the law but these are just a part of the banking system. Working in the commercial bank is very sensitive. If a bank has a lot of employees who have intention to stay, it will be beneficial for the HR management. To reduce the rate of employee resignation in recent years, there are more researchers studying the intention to stay of nurses in foreign countries and Thailand. But they don't have people who have studied about the important keys, such as intention to stay with the bank employees having services and sales to goals. Various news report about the Bank employees in the organization during the past 10 years. There are both positive and negative findings for both employment and resignation. So researchers are interested in the intention to stay with the Bank employees at the operational level.

One thing that is clear in Thai society are popular values. The majority of Thai population always choose to work with reputable organizations. That is because the population believes that when they work with large organizations already famous, the result is good in terms of compensation, position, progress, and good welfare. From the news of the circulation of employees, one may come from the brand of employer and good welfares. So organizational attractiveness is variable that the researcher paid attention to for predicting intention to stay in the job. This study has variables in Thailand. There is no researcher at the level of research. It is close to nature and Thai society for a long time. But it is widely available in foreign countries.

Another interesting feature in the industrial system is when people come to work with organizations that are interesting. Employees will be fit in the job for can work stay with the organization until retirement? Person-job fit is a challenge for human resources departments there are have the process of selecting people to work is appropriate for the job in the role. Intention to stay this work may be one of the variables affecting the employee's intention to stay in the work. Organizational attractiveness is defined as the level of attention that individuals perceive as an organization that aspires to work together. Can lead, the quality of work into the organization and attract the current employees to stay with the organization. The banking system in Thailand often focuses on the service to excellence. In this research, the researcher is interested in studying the personnel who perform the operational level for commercial banks. Organizational attractiveness is a key variable leading to the development of the organization to attract the attention of people who have the ability to service and sales to attend and with the intention to continue with the banks. Person-job fit is important for the human resources department of each bank to be aware of and find the test to measure the appropriate person in the bank. Both of these factors influences employee intentions. When a person is satisfied with their work, they will happily work. Work with intent. The result is quality. The motivation to work. The work will be effective. This will lead to pride in the job and create engagement and loyalty to the organization. This is beneficial to the organization in terms of manpower plan. Budget plans organization security and the good image of the organization.

\section{Purpose}

1) To study the level of organizational attractiveness, person-job fit, and intention to stay.

2) To study the relationship between organizational attractiveness and intention to stay.

3) To study the relationship between person-job fit and intention to stay.

4) To predict intention to stay with organizational attractiveness and person-job fit.

\section{METHODOLOGY}

The purposes of this study are to study level of organizational attractiveness, person-job fit and intention to stay. To study relationship between organizational attractiveness and intention to stay. To study relationship between person-job fit and intention to stay. To predict intention to stay with organizational attractiveness and person-job fit. The samples of the research were employee's total amount 406 people. The analysis and results of the research. In this research, the researcher set the level of significance at .01 levels.

The follow sections describe the methodology used in this study. This includes sampling, data processing, and measurement of variables.

\section{Sampling and Data Processing Population and sample used in research}

The research population is the total population of the research was 76,003 persons (statistics as of January 2018) 
as follows: bank employees A total 21,020 people, bank employees B total 28,971 and employees of bank C total 26,012 people. The sample consisted of 3 commercial bank employees around Bangkok. The sample size was 382 persons. Used Krejcie and Morgan's formula (Krejcie \& Morgan, 1970; Therawut, 2000), the confidence level of $95 \%$ or accepted tolerances at 0.5 .

The researcher then made a stratified sampling (Proportional Stratified Sampling) in proportion to the population of each bank. So, the samples that used in the research af- ter calculated are there were employees of bank A total 105 people, Bank B total 146 people and Bank C total 131 people. For to prevent data loss. Researchers have increased the number of Group-Selection Convenience sample, another 10 percent. Total amount of the sample were 420 peoples. Researcher used the questionnaires amount 420 issue. Respondents were asked about 420 questionnaires. After selected the completely questionnaires total 406 issue show in Table 1

TABLE 1. Sampling and data processing

\begin{tabular}{llllll}
\hline \hline Bank Employees & Population $(\boldsymbol{N})$ & $\begin{array}{l}\text { Calculated } \\
\text { Sample }(\boldsymbol{n})\end{array}$ & $\begin{array}{l}\text { Real Deal } \\
\text { (Add 10\%) }\end{array}$ & $\begin{array}{l}\text { Have Returned } \\
(\boldsymbol{N})\end{array}$ & $\begin{array}{l}\text { Select the Complete } \\
\text { Version }(\boldsymbol{N})\end{array}$ \\
\hline Bank employees A & 21,020 & 105 & 115 & 115 & 110 \\
Bank employees B & 28,971 & 146 & 161 & 161 & 157 \\
Bank employees C & 26,012 & 131 & 144 & 144 & 139 \\
Total & 76,003 & 382 & 420 & 420 & 406 \\
\hline \hline
\end{tabular}

\section{Creating and Developing Research Tools}

The research instrument was constructed as a questionnaire. (Questionnaire) The researcher conducted the following steps;

1 Study theories, theories, and research related to the variables studied. This is a guideline for creating a questionnaire. The concept of research. Ask for advice from a thesis advisor.

2 The questionnaire was designed to be consistent with the terminology used in research, conceptual frameworks and variables used in research.

3 Construct a draft questionnaire.

4 Take the draft questionnaire to the thesis advisor. To review questions to meet the objectives. After being reviewed. Researchers have introduced various proposals to update.

\section{Quality Inspection Tools used in Research}

The researcher applied the modified questionnaire as instructed by the instructor to 3 experts. To examine the validity of language expressions and content validity. Based on the Index Item Objective Congruence (IOC). The criteria for scoring are as follows:

+1 When the question is in line with the definition.

0 Not sure if the question is consistent with the definition?

-1 When the question is not in line with the definition?

Using the formula of Rovinelli and Hambleton (1976) cited in (Somchai, 2010). The IOC value is between 0.50 and 1.00 . If the IOC is 0.50 or higher, then the content validity can be used as a question, but if the IOC is less than 0.50 , then the question consider updating or cutting out the message ac- cording to expert advice.

The researcher to try out a questionnaire from employees of Bank D, there are not the samples used in the research. However, the characteristics were similar to those used in the study.

The data were analyzed by discrimination Power ( $t$-test) Part 2, Part 3 and Part 4 were added to the computer and analyzed. The results obtained from the $t$-test analysis must have a value of $t$ over or equal to 1.75 and thus have the appropriate discriminative power (Kritpredaborisut, 2008). If any item has a $t$ value less than 1.75 , the researcher will cut off the question because there is no discrimination value. The researcher brings the question to the confidence (Reliability) using the Cronbach's Alpha Coefficient and confidence criteria of 0.7 (Kranlong, 2012). Before, the complete questionnaire was used to collect the actual data.

\begin{tabular}{ll}
\hline \hline Questionnaire & Cronbach's Alpha \\
\hline Intention to stay & .929 \\
Organizational attractiveness & .928 \\
Person job fit & .945 \\
Need supplies fit & .900 \\
Demand ability fit & .922 \\
\hline \hline
\end{tabular}

\section{Instrumentation}

The instrument used to collect data for this study was a questionnaire. The characteristics of the questionnaire are divided into 4 parts. Part 1 Personality questionnaire a question about personal attributes. Checklist 5 items, in- 
cluding gender, age, education, work, experience, salary. Part 2 A questionnaire about Organizational Attractiveness. The questionnaires were rated as rating scale. There are 5 levels of answers are the highest level, very level, medium, low level, minimal level.

Part 3 Questionnaire about Person-Job Fit. The questionnaire was divided into 2 aspects: the aspect Need-Supplies Fit 8 question and the aspect Demand-Ability Fit 11 question. The questionnaires were classified as rating scale. There are 5 levels of answers are the highest level, very level, medium, low level, minimal level.

Part 4: The questionnaire about Intention to stay. The questionnaires were rated as rating scale. There are 5 levels of answers are the highest level, very level, medium, low level, minimal level.

\section{Data Analysis}

1. Frequency and percentage are used to analyze and present information about the individual characteristics of the sample there are gender, age, education level, work experience, salary.

2. Mean and standard deviation. Used in descriptive analysis organizational attractiveness, person-job fit and intention to stay.

3. Finding the correlation coefficient (Pearson's Correlation Coefficient).

4. Stepwise multiple regression Analysis use predictive analysis to predict intention to stay with organizational attractiveness and person-job fit.

\section{RESULTS}

\section{Analysis of Data on Personal Factors}

The analysis of personal factors, by age, gender, education level, work experience and salary From Table 2.

It was found there are female total 314 peoples, calculate were $77.34 \%$ and male total 92 peoples, calculate were $22.66 \%$.

It was found that most of the employees in commercial bank have 25-24 year old there are 282 peoples or $69.46 \%$, followed by $64-45$ years old or $15.76 \%, 45$ years or over 43 peoples or $10.59 \%$.

It was found that most of the employees in commercial bank have work experience more than 10 years amount 251 people or $61.82 \%$, inferior to 6-10 years amount 89 peoples or $21.92 \%$, next below to $1-5$ years have 60 peoples or $14.78 \%$ and less than 1 year, 6 persons or $1.48 \%$.

It was found that most of the employees in commercial bank have salaries of between 20,001-30,000 B amount 215 peoples or $52.96 \%$, secondary to $15,000-20,000$ B amount 102 peoples or $25.12 \%$, employees have salaries between $30,001-40,000$ B amount 67 peoples or $15.76 \%$, salaries more than 40,000 B amount 25 peoples or $6.16 \%$.

It was found that most of the commercial bank employees had the education on bachelor degree amount 363 peoples calculate were $89.41 \%$, inferior to postgraduate degree 39 peoples or $9.60 \%$, next below is undergrad degree 4 peoples or $0.99 \%$.

TABLE 2. Data on personal factors

\begin{tabular}{lll}
\hline \hline Sample & Number & Percent \\
\hline Gender & & \\
Male & 92 & 22.66 \\
Female & 314 & 77.34 \\
Age & & \\
Less than 25 years & 17 & 4.19 \\
25-34 years & 282 & 69.46 \\
35-44 years & 64 & 15.76 \\
45 years or over & 43 & 10.59 \\
Work experience & & \\
Less than 1 year & 6 & 1.48 \\
1-5 years & 60 & 14.78 \\
6-10 years & 89 & 21.92 \\
More than 10 years & 251 & 61.82 \\
Salary & & \\
15,000-20,000 & 102 & 25.12 \\
20,001-30,000 & 215 & 52.96 \\
30,001-40,000 & 64 & 15.76 \\
More than 40,000 & 25 & 6.16 \\
Education & & \\
Undergrad degree & 4 & 0.99 \\
Bachelor & 363 & 89.41 \\
Postgraduate & 39 & 9.60 \\
Included & 406 & 100 \\
\hline \hline & & \\
\hline
\end{tabular}

\section{Analysis of Data on Average, Standard Deviation and Level}

From Table 3 Intention to stay were at high level. Organizational attractiveness were at high level and Person-Job Fit were at high level. 
TABLE 3. Analysis of data

\begin{tabular}{llll}
\hline \hline Variable & $\bar{x}$ & $\boldsymbol{S . D}$ & Degree \\
\hline Intention to stay & 3.79 & 0.786 & High level \\
Organizational attractiveness & 4.28 & 1.296 & High Level \\
Person job fit & 4.17 & .901 & High level \\
\hline \hline
\end{tabular}

\section{Analysis of Data to Test Hypothesis}

Assumptions 1: Organizational attractiveness and intention to stay of the employees in commercial banks are relation. From Table 4 it was found that organizational attractiveness and intention to stay of the employees in commercial banks were positively correlated. At the .01 level $(r=.598)$ accounted for $34.69 \%$.

TABLE 4. Analysis of data to test hypothesis

\begin{tabular}{llll}
\hline \hline Organizational Attractiveness & \multicolumn{3}{l}{ Intention to Stay } \\
\cline { 2 - 4 } & $\boldsymbol{r}$ & $r^{2} \times \mathbf{1 0 0}$ & $\boldsymbol{p}$ \\
\hline Organizational Attractiveness & $.589^{* *}$ & 34.69 & .000 \\
\hline \hline ** Significant at the .01 level & & &
\end{tabular}

The assumption is that if the banker have to organizational attractiveness and intention to stay is to have a lot. If the banker have to organizational Attractiveness is low level.
The intention to stay of the employees will be less with it. Assumptions 2: Person job-fit and intention to stay of the employees in commercial banks are relation.

TABLE 5. Analysis of data to test hypothesis

\begin{tabular}{llll}
\hline \hline Person Job Fit & \multicolumn{3}{l}{ Intention to Stay } \\
\cline { 2 - 4 } & $\boldsymbol{r}$ & $r^{2} \times \mathbf{1 0 0}$ & $\boldsymbol{p}$ \\
\hline Need supplies fit & $.372^{* *}$ & 13.84 & .000 \\
Demand ability fit & $.493^{* *}$ & 24.30 & .000 \\
Included & $.612^{* *}$ & 37.45 & .000 \\
\hline \hline
\end{tabular}

** Significant at the .01 level

From Table 5 it was found that Person Job-Fit and Intention to stay employees of the commercial banks were positively correlated. There was a statistically significant difference at .01 level ( $r=.612$ ), or $37.45 \%$.

The assumption is that if the bank employee. Person job-fit and intention to stay of the employee is high. If Intention to stay Low Level. The intention to stay of the employees is to be less.

\section{Analysis of Data to Predictions}

In this hypothesis test, the researchers used three predictive variables, namely, Organizational Attractiveness and Person Job-Fit in two areas. The results of multiple regression analysis are as follows.

From Table 6 Found the variable organizational attractiveness and Person Job-Fit. The two regression equations were applied to the regression equation in two steps, with a statistically significant $F$.

When considering the coefficient of determination $\left(R^{2}\right)$, it was found that;
Step 1 Variables Organizational attractiveness can predict Intention to stay of $34.7 \%$ of employees. Step 2 When adding variables Person Job-Fit Demand-Ability Fit can predict Intention to stay of $40.3 \%$ of employees.

Therefore, the optimal regression equation is Intention to stay $=a+b_{1}$ organizational attractiveness + Person Job-Fit Demand-Ability Fit.

When

$a=$ Constant

$b_{1}=$ Regression coefficient organizational attractiveness

$b_{2}=$ Regression coefficient Person Job-Fit Demand-Ability Fit

Intention to stay $=.329+.501$ organizational attractiveness + Person Job-Fit Demand-Ability Fit From the above equation, it can be explained that if 501 organizational attractiveness increases by 1 , it will increase Intention to stay. If Person Job-Fit Demand-Ability Fit increased 1 point, it is Intention to stay increased 319 units with a constant value of .329. 
When converting raw scores into standard scores, $Z$-scores will have the predicted Intention to stay of the bank employee. The standard score is as follows. Intention to stay =
457 (Organizational attractiveness) + .272 (Person Job-Fit Demand-Ability Fit) .The standard for the job is .457 .

TABLE 6. Analysis of data to predictions

\begin{tabular}{llllllll}
\hline \hline Steps & Predictive Variables & $R$ & $R^{2}$ & Adjust $R^{2}$ & $S . E \cdot$ est & $\boldsymbol{F}$ & p \\
\hline 1 & Organizational Attractiveness & .589 & .347 & .345 & .472 & $214.296^{* *}$ & .000 \\
2 & $\begin{array}{l}\text { Organizational Attractiveness } \\
\text { Person Job-Fit Demand-Ability Fit }\end{array}$ & .635 & .403 & .400 & .452 & $136.116^{* *}$ & .000 \\
\hline \hline
\end{tabular}

** Significant at the .01 level

\section{DISCUSSION \& CONCLUSION}

Organizational Attractiveness and Intention to stay of the employees in commercial banks are related. Results of statistical analysis to find the relationship between organizational attractiveness and intention to stay based on the survey results.

Organizational Attractiveness and Intention to stay of the employees in commercial banks were positively correlated high level, the statistical significance was .01, which was in line with the assumptions.

Researchers is think organizational attractiveness is what makes employees feel like they come to work with the organization. Which matches the research Rousseau (2008) because people want to work with the organization may be because of welfare. Higher wages and proud of the work of this organization. May be good when it comes to being a part of an organization that is attractive, famous, dignity, strong and stable, advanced in the work. Minchington (2011) said organizational attractiveness it helps to create more consistent work experience and communication because the organization has quality employees working in the organization. Which matches the research Berthon, Ewing, and Hah (2005) said organizational attractiveness means "visible benefits, which are likely to be seen by potential employers. To work for a specific organization "or a potential organization, and employees recognize that the organization is a good place to work. Which matches the research Jiang and Iles (2011) said organizational attractiveness "The power that draws employees' attention. And stimulate the retention of existing employees. These things make employees stay in the organization.

In the view of the researcher, When organizational attractiveness with high-level bank employees. That's what shows the employees in the organization feel like they want to continue. It is believed that the organization is a wellknown organization with a good and stable organization. In terms of compensation, welfare, training to improve the po- tential. It is also an organization that outsiders pay attention and desire to work. So that organizational attractiveness is positively correlated with the Intention to stay of the bank employees.

Person Job-Fit and Intention to stay the employees of the commercial banks are related. Results of statistical analysis to find the relationship between person job-fit and intention to stay based on the survey results.

Person Job-Fit and Intention to stay employees of the commercial banks were positively correlated high level, the statistical significance was .01, which was in line with the assumptions. Researcher is think person job-fit is what makes it is the consistency between the person's attributes and the job's attributes. This is due to the individual's ability to work, such as skills, knowledge, ability of the person in accordance with the needs of the job. Which matches the research (Edwards, 1991) because when employees come to work in accordance with the characteristics of the organization, it will make employees satisfaction with the organization. And when the staff satisfaction. Or engagement, then it would make employees want to work with the organization. Without a caveat or any rules that force employees. The employee is determined to remain in the job based on the concept Mitchell and Lee (2001). Which matches the research Reed, Kratchman, and Strawser (1994) said person job-fit is a positive relationship that employees are intention to stay in the organization. Parsa, Tesone, and Templeton (2009) Believe the defect of the organization is that most of the lost employees are from person job-fit, Need Supplies Fit. Which matches the research Sekiguchi (2004) said the internal needs of a person and their abilities are their personal qualities in their ability to meet their needs. The needs of the job knowledge. And the ability needed for the job. Throughout the recruitment and selection process, these features are evaluated from CVs, interviews, or other tools. Used in the selection. While the elements of the internal demand concept and the factors that the organization 
has to offer are the desires of the individual. And the features of the work that meet these desires. Which matches the research Mustapha, Ahmad, Uli, and Iis (2010) If the employee is intention to stay in the job. This will result in high resignation. Affect the efficiency of the organization.

In the view of the researcher, when the bank employee is person job-fit, whether it is need supplies fit and demandability fit All of these factors were related intention to stay of the bank employees to remain at the high level. That is what shows. Most of the respondents were employees working in an organization that needed specialized knowledge and skills to work with the organization. As a result, the intention to stay in the job. The banker should graduate in the field that meets the needs of the job. Or specific features of the job such as business management, accounting, finance, marketing, economics, etc. Other than that, if the employee does not graduate from the aforementioned subjects. The researcher found that employees should have the personal ability to work in line with their needs. And this is why the sample is committed and the intention to stay. There- fore, person job-fit was positively correlated with intention to stay of the bank employees.

Organizational attractiveness and intention to stay in at least one variable can predict the intention to stay of the bank employees. The results of multiple regression analysis showed that Organizational Attractiveness, Person JobFit, Demand-Ability Fit can jointly predict the intentions of the employees of commercial banks $40.3 \%$. This is based on assumptions placed. Which matches the research W. C. Tsai and Yang (2010) said organizational attractiveness can predict whether a candidate is willing to accept employment offers in one organization. And want to work in the same organization without a caveat. Employees in the organization are willing to stay in the job. In order to make yourself progress. Stable and proud to be part of the organization with people interested. Ehrhart and Ziegert (2005) Explain organizational attractiveness as an effective candidate for the organization. This is a great place to work. It is where people want to work.

\begin{tabular}{ll}
\hline \hline Research Hypothesis & Test Result \\
\hline $\begin{array}{l}\text { 1. Organizational Attractiveness and Intention to stay the } \\
\text { employees of the commercial banks are related Accept the }\end{array}$ & \\
hypothesis. & \\
2. Person Job-Fit and Intention to stay the employees of the & $(r=.612, p<.01)$ \\
commercial banks are related Accept the hypothesis. & \\
3. Organizational attractiveness and Person Job-Fit in at least & Accept the hypothesis. \\
one variable can predict Intention to stay of the bank employ- \\
ees.
\end{tabular}

\section{SUGGESTIONS}

1. This study was conducted with a sample of bank employees. It may be a limited sample. The researcher thinks that it should be done with more diverse samples such as employees in state enterprises, government officials, employees, private companies, etc.

2. Should be studied factors or other variables. That may affect the intention to remain in the work, such as organizational culture. Organizational Commitment Relationships among colleagues, workload, happiness in work, etc.

3 . In the next study, research should be conducted on qualitative research. By in-depth interview for more information on research.

4. In the next research. The attitude of the researcher. Should develop a questionnaire of intent. To be used in human resources in organizations and industries. In the an- nual staff inquiry. To know the purpose of the employee's mind whether they want to stay with the organization or not. The questionnaire used in the research. It may be more profitable than it was. The question is not just to know. To analyze it is a question to develop.

\section{THE BENEFITS OF RESEARCH}

1. Know organizational attractiveness. Appropriateness of work and intention to stay of bank employees.

2. Know organizational attractiveness relationship and the intention to stay of the bank employees.

3. Know person job-fit relationship and the intention to stay of the bank employees.

4. Knowing the factors that predicted the intention to stay of bank employees. With organizational attractiveness and person job-fit. This will lead to the development of organizations in various areas to other organizations. 
5. It provides a guideline for the development of procedures for the recruitment and selection of Human Resources staff.
Including manpower planning. Budget planning And the good image of the organization. To benefit other organizations.

\section{REFERENCES}

Berthon, P., Ewing, M., \& Hah, L. L. (2005). Captivating company: Dimensions of attractiveness in employer branding. International Journal of Advertising, 24(2), 151-172. doi:https://doi.org/10.1080/02650487.2005.11072912

Dasig Jr, D. (2017). A frontier in organizational and business process innovation in service management through lean six sigma Kaizen project implementation. Journal of Administrative and Business Studies, 3(6), 263-283. doi:https:// doi.org/10.20474/jabs-3.6.2

Edwards, J. R. (1991). Person job fit: A conceptual integration, literature review, and methodological critique. In C. L. Cooper \& I. T. Robertson (Eds.), International review of industrial and organizational psychology. International review of industrial and organizational psychology. Oxford, England: John Wiley \& Sons.

Ehrhart, K. H., \& Ziegert, J. C. (2005). Why are individuals attracted to organizations? Journal of Management, 31(6), 901-919. doi:https://doi.org/10.1177/0149206305279759

Husain, Y. S., \& Husin, N. H. (2017). Knowledge sharing behavior, job attitudes, OCB and organizational learning culture. Journal of Administrative and Business Studies, 3(4), 162-170. doi:https://doi.org/10.20474/jabs-3.4.1

Jiang, T., \& Iles, P. (2011). Employer-brand equity, organizational attractiveness and talent management in the zhejiang private sector, china. Journal of Technology Management in China, 6(1), 97-110. doi:https://doi.org/10.1108/ 17468771111105686

Kranlong, S. (2012). Test of confidence questionnaire. Retrieved from https://goo.gl/SzF4ws (accessed on 25 May 2018)

Krejcie, R. V., \& Morgan, D. W. (1970). Determining sample size for research activities. Educational and Psychological Measurement, 30(3), 607-610. doi:https://doi.org/10.1177/001316447003000308

Kritpredaborisut, B. (2008). Research methods in social sciences. Bangkok, Thiland: Chamchuri Product.

Kulesa, P. (2003). Keeping the good apples. Security Management, 47(8), 32-32.

Li, X. (2017). Cross-cultural interaction and job satisfaction in cross-cultural organizations: A case study of two Thai companies founded and managed by Chinese people. Journal of Administrative and Business Studies, 3(6), 255-262. doi:https://doi.org/10.20474/jabs-3.6.1

Mathis, R. L. (2006). Human resorces management: Manajemen sumber daya manusia (terjemahan). Jakarta, Indonesia: Salemba Empat.

Minchington, B. (2011). Employer branding without borders: A pathway to corporate success. Retrieved from https:// goo.gl/DVXgbg (accessed on 12 July 2016)

Mitchell, T. R., \& Lee, T. W. (2001). 5. the unfolding model of voluntary turnover and job embeddedness: Foundations for a comprehensive theory of attachment. Research in Organizational Behavior, 23, 189-246. doi:https://doi.org/ 10.1016/s0191-3085(01)23006-8

Mustapha, N., Ahmad, A., Uli, J., \& Iis, K. (2010). Job characteristics as antecedents of intention to stay and mediating effects of work family facilitation and family satisfaction among single mothers in malaysia. International Journal of Business and Social Science, 1(3), 34-67.

Parsa, H., Tesone, D., \& Templeton, A. (2009). All employees are not created equal: An alternative method of assessing employee turnover. Journal of Foodservice Business Research, 12(4), 317-330. doi:https://doi.org/10.1080/ 15378020903344265

Reed, S. A., Kratchman, S. H., \& Strawser, R. H. (1994). Job satisfaction, organizational commitment, and turnover intentions of united states accountants: The impact of locus of control and gender. Accounting, Auditing \& Accountability Journal, 7(1), 31-58. doi:https://doi.org/10.1108/09513579410050371

Rehman, S. (2017). Impact of career development on organizational commitment. International Journal of Business and Administrative Studies, 3(3), 100-111. doi:https://doi.org/10.20469/ijbas.3.10005-1

Rousseau, P. (2008). Talent chooses prestige over pay. vlerick leuven gent, press release. Retrieved from https://goo.gl/ sMcqZb (accessed on 8 December 2011) 
Rovinelli, R. J., \& Hambleton, R. K. (1976). On the use of content specialists in the assessment of criterion-referenced test item validity. Dutch Journal of Educational Research, 2(6), 49-60.

Sekiguchi, T. (2004). Person organization fit and person-job fit in employee selection: A review of the literature. Osaka Keidai Ronshu, 54(6), 179-196. doi:https://doi.org/10.5539/ass.v11n2p313

Somchai, V. K. S. (2010). Research methods in behavioral sciences and social sciences. Bangkok, Thiland: Artsornsinkranpem.

Taiwan, A., Na. Nan, K., \& Ngudgratoke, S. (2017). Relationship among personality, transformational leadership, percerived organizational support, expatriate adjustment, and expatriate performance. International Journal of Business and Administrative Studies, 3(4), 129-141. doi:https://doi.org/10.20469/ijbas.3.10001-4

Therawut, A. (2000). Research methods in behavioral sciences and social. Si Racha, Thiland: Ubon Ratchathani Rajabhat University.

Tsai, M. (2017). The influence of loyalty, participation and obedience on organizational citizenship behavior. International Journal of Business and Economic Affairs, 2(1), 67-76. doi:https://doi.org/10.24088/ijbea-2017-21009

Tsai, W. C., \& Yang, I. W. (2010). Does image matter to different job applicants? The influences of corporate image and applicant individual differences on organizational attractiveness. International Journal of Selection and Assessment, 18(1), 48-63. doi:https://doi.org/10.1111/j.1468-2389.2010.00488.x 